\title{
Origin of intraventricular haemorrhage in the preterm infant
}

\author{
G. HAMBLETON* and J. S. WIGGLESWORTH \\ From the Department of Paediatrics and Neonatal Medicine, Hammersmith Hospital, London
}

Hambleton, G., and Wigglesworth, J. S. (1976). Archives of Disease in Childhood, 51, 651. Origin of intraventricular haemorrhage in the preterm infant. A technique has been developed for the injection and stereomicroscopic examination of blood vessels in the preterm newborn brain. Using this technique it can be seen that in the immature brain there is a rich capillary bed in the germinal layer region supplied mainly by Heubner's artery. Capillary channels drain directly into the terminal vein and its main branches.

Study of 19 cases with spontaneous germinal layer haemorrhage (GLH) with or without intraventricular haemorrhage (IVH) failed to show rupture of the terminal vein or germinal layer infarction. In babies of up to 28 weeks' gestation GLH developed most frequently over the body of the caudate nucleus, whereas in babies of 29 weeks' gestation or more the haemorrhages were usually over the head of the caudate nucleus. Histological study of 10 cases of GLH failed to show rupture either of arteries or veins, though evidence of rupture at a capillary-vein junction was seen in one case and masses of fibrin adjacent to the vein wall in 2 others.

Injection through the carotid artery caused prominent leaks of injection mass within the germinal layer capillary bed, often adjacent to the veins. Injection through the jugular veins in 2 cases failed to rupture the terminal vein but caused multiple vein ruptures at the junction of deep and cortical venous systems. Additional small ruptures in the germinal layer occurred in one of the cases only. It is suggested that the capillaries within the germinal layer may be ruptured by a rise in arterial pressure, particularly in conditions of hypercapnia and hypoxia.

Recent advances in management of the respiratory distress syndrome have considerably improved the outlook for small preterm infants. This success is limited by the inability to prevent or treat massive intraventricular haemorrhage (IVH) which may now have become the most frequent cause of death in such infants (Reynolds and Taghizadeh, 1974). Determination of the pathogenesis of the condition seems to be an obvious prerequisite for any attempt to prevent it. There has, however, been a total lack of agreement about the origin of the haemorrhage.

Most workers accept that the primary lesion involves bleeding into the germinal layer beneath the ependyma of the lateral ventricle over the head and body of the caudate nucleus, with subsequent rupture of the haematoma into the ventricular

Received 22 December 1975.

^Present address: Park Hospital, Davyhulme, Manchester. system. It has been claimed that the haemorrhage originates from rupture of immature vessels in the germinal layer (Gruenwald, 1951), rupture of the terminal vein (Gröntoft, 1953; 1954; Cole et al., 1974), or germinal layer infarction (Towbin, 1968). Venous thrombosis has been implicated as playing an important role (Larroche, 1964). A further suggestion has been that arterial pressure might be directly transmitted to the veins through the perforating cortical arteries (S. Strich, personal communication, 1966).

In order to establish the basic anatomy of IVH and other cerebral vascular lesions we have studied the cerebral blood vessels in preterm infants who come to necropsy. This communication describes macroscopical and preliminary histological findings in relation to germinal layer haemorrhage (GLH) and IVH. 


\section{Materials and methods}

In order to examine the relation of haemorrhages to the blood vessels the following injection technique has been devised. The internal carotid arteries and jugular veins are isolated at necropsy and coloured barium gelatin solutions (Colorpaque, Pilot Chemical Co. Ltd.) injected into either arteries or veins through a nylon intravenous cannula (size 4-5 French). The usual procedure has been to inject a solution of red Colorpaque with $3 \%$ gelatine into the carotid arteries until Colorpaque is seen draining from the jugular veins, and to follow this by injection of 3-6 ml of a solution of blue Colorpaque with $5 \%$ gelatine through the same cannula. The aim is to displace red solution from arteries into the capillaries and veins and to leave the arteries coloured blue. During the injection procedure the vertebral arteries are clamped off to avoid excessive leakage of injection mass into the body tisues. In most of the cases reported in this paper injection was carried out using a hand-held syringe, but in 6 instances injection was performed at known pressures of $60-90$ $\mathrm{mmHg}$ using a simple pressure apparatus.

After injection the brain is fixed by suspension in $10 \%$ formol saline for 1-4 weeks. After fixation the cerebral hemispheres are separated and are usually handled differently. The medial aspect of one hemisphere is dissected away to expose the lateral wall of the lateral ventricle with the caudate nucleus. Thin slices (2-5 $\mathrm{mm}$ ) of the opposite hemisphere are taken in the coronal plane without prior dissection. The blocks of both cerebral hemispheres are then taken through the following series of solutions (a modification of the method of Spalteholz; see Edwards and Edwards, 1959): 50\% alcohol; 70\% alcohol; 70\% alcohol/cellosolve (2 ethoxy-ethanol) $2: 1 ; 70 \%$ alcohol/cellosolve $1: 2$; cellosolve ( 2 changes); methyl salicylate ( 2 changes). At the end of the procedure, which takes about 2 weeks, the methyl salicylate has rendered the tissue translucent with clearly defined vessels. The blocks are retained in methyl salicylate and examined under the stereomicroscope (preferably with both incident and substage illumination). The cleared material may be further sliced or dissected to define vascular antomy in more detail. Blocks may be taken for histology in the normal way but it is helpful to take them through toluene to remove methyl salicylate and traces of cellosolve before embedding in wax.

Of 34 brains studied so far, injection was performed through the arteries in 32 and injection by the jugular veins was attempted in 2 . Gestational ages of the infants ranged from 24 to 40 weeks and death had occurred at from 8 minutes to 10 days postnatally. After stereomicroscopic study, blocks of 16 of these cases were embedded in paraffin wax/beeswax/dental wax mixture and sectioned for histological examination. 5 subependymal haemorrhages were subjected to serial or step sectioning (section thickness ranged from 7 to 25 $\mu \mathrm{m})$ and examined after staining with haematoxylin and eosin, or van Gieson's stain. In addition, blocks of 5 brains showing germinal layer haemorrhages, but which had not been injected, were embedded and sectioned after clearing in methyl salicylate.

\section{Results}

Vascular anatomy of germinal layer. Brains of babies of up to 32 weeks' gestational age were seen to have a rich capillary bed in the subependymal region, particularly over the lower half of the head of the caudate nucleus. The capillary bed is supplied mainly by Heubner's artery, a branch of the anterior cerebral artery, though terminal branches of the lateral striate arteries (middle cerebral artery), and the anterior choroidal artery (internal carotid or middle cerebral artery) also supply this capillary bed in part (Fig. 1). Venous drainage is via the

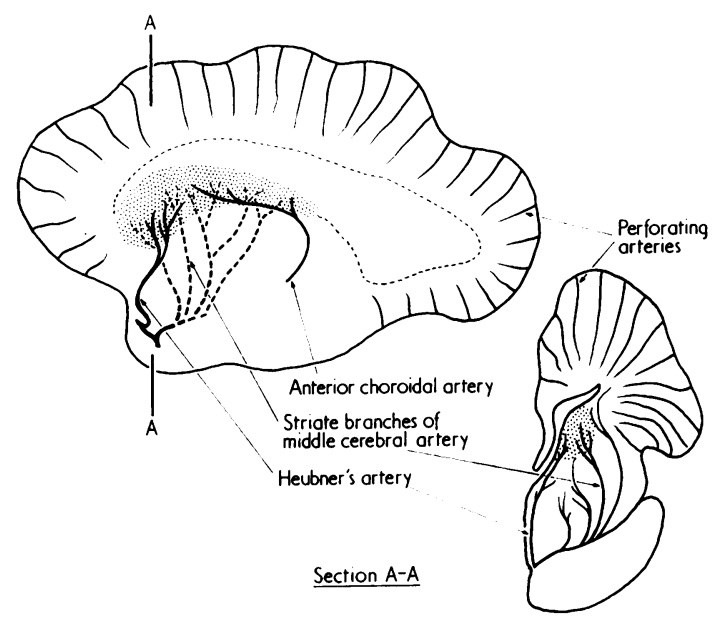

FIG. 1. Arterial supply to caudate nucleus; 30 weeks' gestation.

terminal vein branches into the internal cerebral vein (Fig. 2). Fine vessels, of capillary calibre, could be seen to enter major terminal vein branches directly, usually at right angles, both on stereomicroscopy and on histological section (Fig. 3). As small arteries, capillaries, and veins in the developing brain all have a simple endothelial wall structure the stereomicroscopic study was particularly helpful in establishing the identity of different vessels which were then readily located in serial sections. Above 32 weeks' gestational age, with progressive diminution of the germinal layer, the subependymal capillary bed gradually merges with that of the rest of the corpus striatum. The vascular anatomy will be reported in greater detail elsewhere. 
Origin of intraventricular haemorrhage in the preterm infant

TABLE

Clinical data and sites of haemorrhage in injected brains with $G L H$

\begin{tabular}{|c|c|c|c|c|c|c|c|}
\hline \multirow{2}{*}{ Case } & \multirow{2}{*}{ Sex } & \multirow{2}{*}{$\begin{array}{l}\text { Gestational } \\
\text { age }(w)\end{array}$} & \multirow{2}{*}{$\begin{array}{c}\text { Birthweight } \\
\text { (g) }\end{array}$} & \multirow{2}{*}{$\begin{array}{l}\text { Age at } \\
\text { death } \\
\text { (h) }\end{array}$} & \multicolumn{2}{|c|}{ Site of GLH } & \multirow{2}{*}{ IVH } \\
\hline & & & & & $\mathbf{R}$ caudate & L caudate & \\
\hline $\begin{array}{c}1 \\
2 \\
3 \\
4 \\
5 \\
6 \\
7 \\
8^{\star} \\
9^{\star} \\
10 \\
11 \\
12 \\
13 \\
14 \\
15 \\
16 \\
17 \\
18 \\
19\end{array}$ & $\begin{array}{c}\mathbf{M} \\
\mathbf{F} \\
\mathbf{M} \\
\mathbf{M} \\
\mathbf{F} \\
\mathbf{M} \\
\mathbf{M} \\
\mathbf{F} \\
\mathbf{M} \\
\mathbf{F} \\
\mathbf{F} \\
\mathbf{M} \\
\mathbf{F} \\
\mathbf{F} \\
\mathbf{F} \\
\mathbf{F} \\
\mathbf{M} \\
\mathbf{M} \\
\mathbf{M}\end{array}$ & $\begin{array}{l}29 \\
30 \\
37 \\
28 \\
24 \\
33 \\
34 \\
30 \\
37 \\
28 \\
30 \\
29 \\
27 \\
27 \\
30 \\
30 \\
30 \\
30 \\
30\end{array}$ & $\begin{array}{r}1180 \\
1240 \\
3250 \\
1200 \\
750 \\
3000 \\
2080 \\
1770 \\
2840 \\
1100 \\
1260 \\
1340 \\
940 \\
940 \\
1160 \\
1350 \\
1160 \\
1110 \\
1040\end{array}$ & $\begin{array}{c}38 \\
16 \\
57 \\
22 \\
20 \\
8 \\
60 \\
16 \\
56 \\
61 \\
43 \\
10 \\
8 d \\
48 \\
56 \\
9 d \\
8 \\
20 \\
52\end{array}$ & $\begin{array}{l}\text { Head } \\
\text { Head } \\
\text { Body } \\
\text { Head } \\
\text { Head } \\
\text { Head } \\
\text { Throughout } \\
\text { Head } \\
\text { Body } \\
\text { Body } \\
\text { Body } \\
\text { - } \\
\text { Head } \\
\text { Head } \\
\text { Head } \\
\text { Head }\end{array}$ & $\begin{array}{l}\text { Head } \\
\text { Body } \\
\text { Body } \\
\text { Head } \\
- \\
\text { Head } \\
\text { Body } \\
\text { Head } \\
\text { Head } \\
\text { Body } \\
\text { Head } \\
\text { Head } \\
\text { Head } \\
\text { Head } \\
\text { Head }\end{array}$ & $\begin{array}{l}+ \\
+ \\
- \\
+ \\
+ \\
- \\
+ \\
- \\
- \\
+ \\
+ \\
+ \\
+ \\
+ \\
+ \\
+ \\
+ \\
+ \\
+\end{array}$ \\
\hline
\end{tabular}

^Indicates cases where injection was performed via jugular veins. All others were injected through carotid arteries.

GLH, germinal layer haemorrhage; IVH, intraventricular haemorrhage.

Site of GLHs. GLHs were seen in 19 brains, unilateral in 9 and bilateral in 10 (see Table). There was usually only one large GLH within a hemisphere, though there were often additional petechiae surrounding the main lesion or occasionally elsewhere in the germinal layer. In 15 brains one or both of the haemorrhages had ruptured into the ventricular system. It can be seen from the Table that bleeding originated over the head of the caudate nucleus in 29 instances (in 15 infants) and

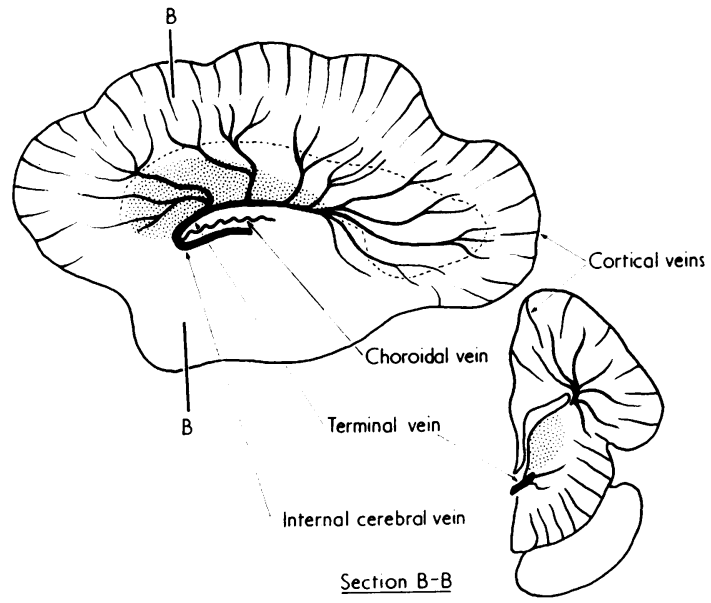

FIG. 2.-Veins related to caudate nucleus; 30 weeks' gestation. over the body of the caudate nucleus in 8 instances (in 6 infants). In one infant (Case 10) haemorrhage involved the whole of the right caudate nucleus. Haemorrhages over the body of the caudate nucleus were seen in the least mature infants (24-28 weeks' gestational age) while haemorrhages over the head of the caudate nucleus were seen in the infants of 29 weeks' gestational age or more. This gestational age difference proved to be statistically significant irrespective of whether the 2 cases with both types of lesion were included in the analysis or not $(P<0.01$

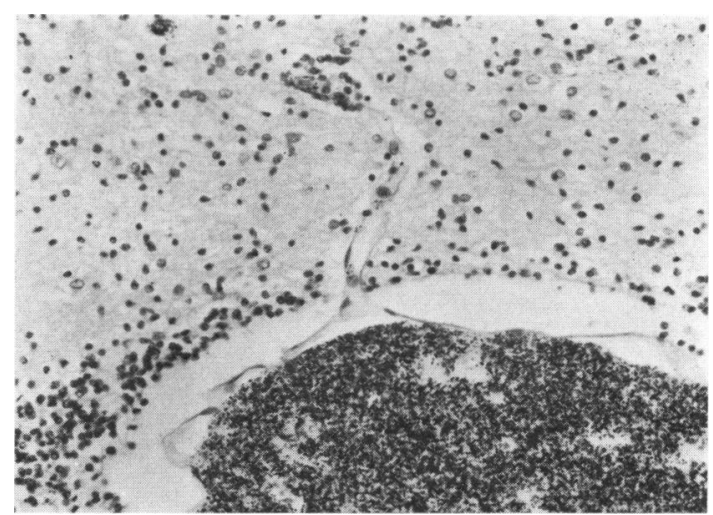

Fig. 3.-Case 6 (see Table). Capillary-vein junction at margin of germinal layer. Injection mass shows as black granules within vein. Note identical structure of capillary and vein walls. (H. and E. $\times 230$.) 


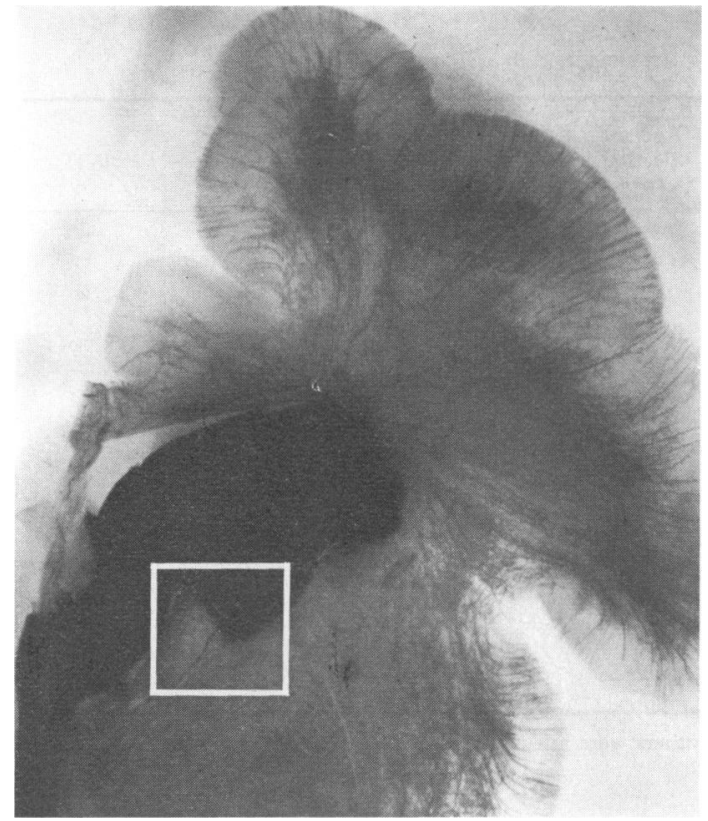

FIG. 4.-Case 1 (cleared). Coronal slice of left cerebrum showing GLH and IVH. For inset see Fig. 5.

by Student's ' $t$ ', or by Wilcoxon's test). The area involved in the anterior GLH corresponded closely to the area of the capillary bed supplied by Heub-

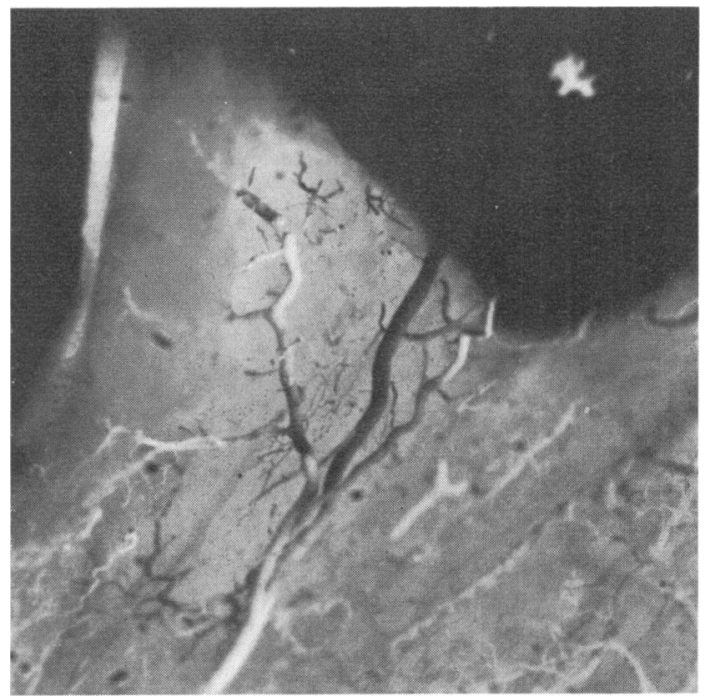

Fig. 5.-Inset from Fig. 4 showing branches of Heubner's artery entering the GLH. Compare with Fig. 10 from the opposite hemisphere. $(\times 27$.

ner's artery (Figs. 4 and 5), whereas the remainder corresponded to areas supplied by lateral striate arteries or the anterior choroidal artery. Typical lesions at each site are illustrated in Figs. 6 and 7. The terminal vein and its main tributaries were

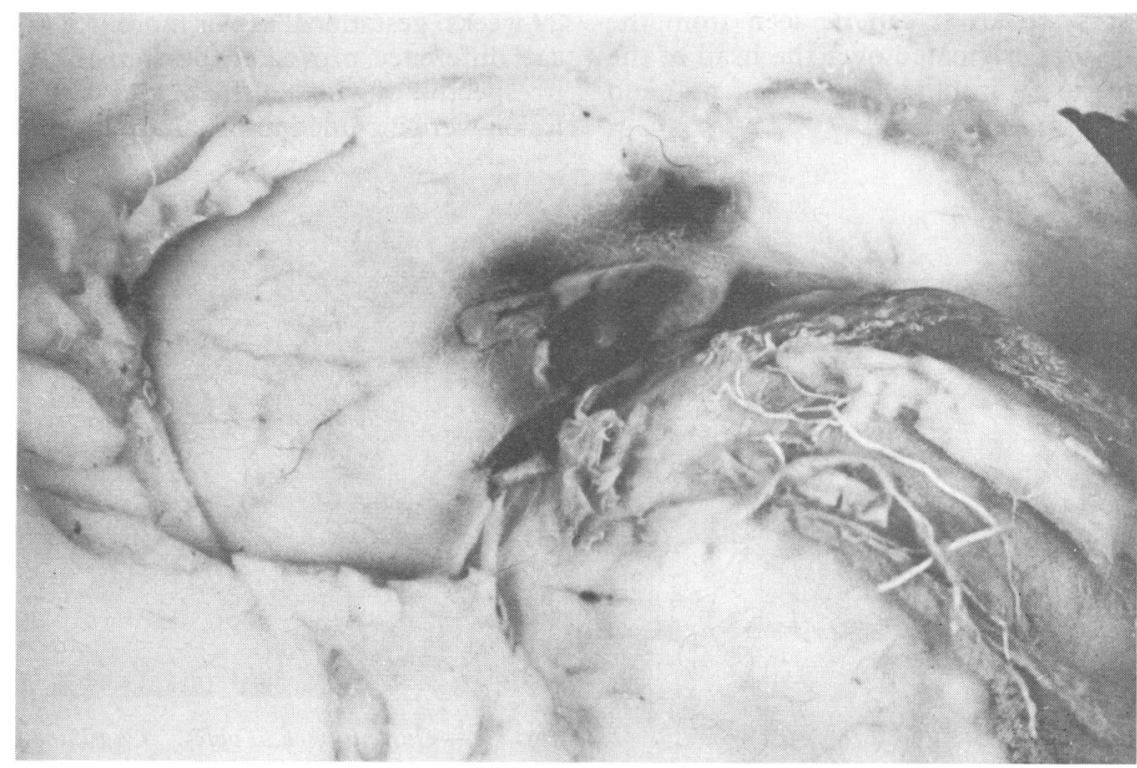

Fig. 6.-Case 2 (uncleared). GLH over the head of the right caudate nucleus. IVH has been removed. Compare with distribution of Heubner's artery shown in Fig. 1. 


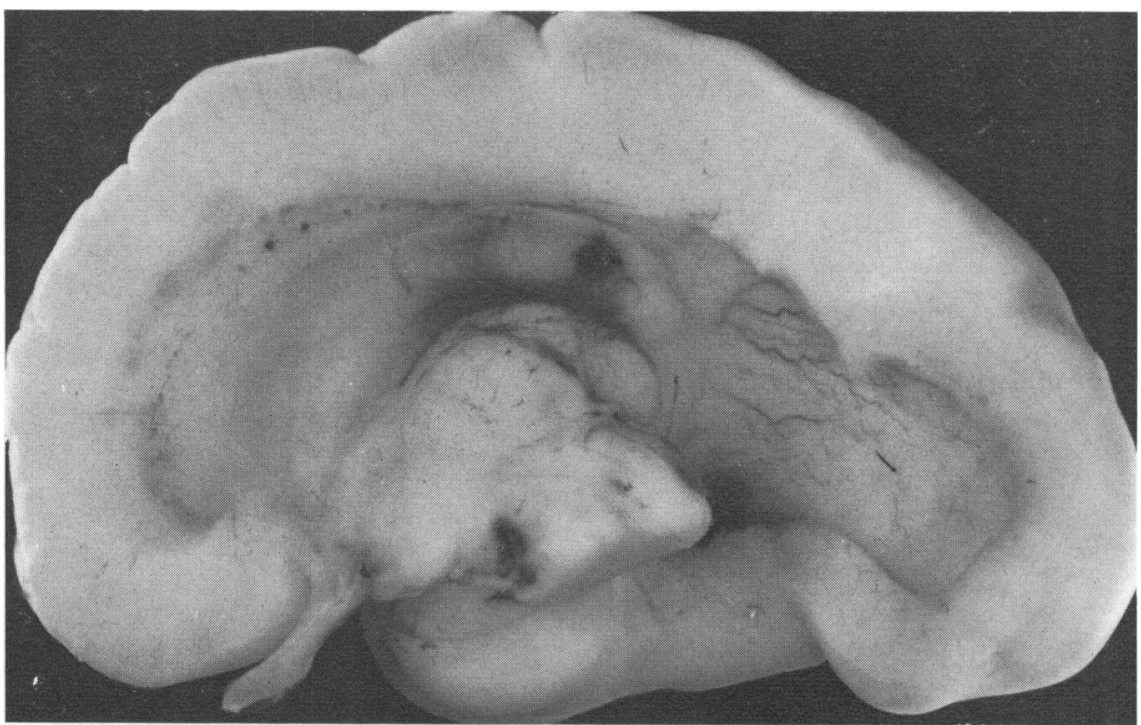

filled by the injection mass (Fig. 8) and could readily be seen to be intact in all but 7 instances ( 4 infants). Failure to inject the vein adequately in these cases was associated with pre-existing massive GLH. In 2 instances histological examination of serial sections was performed and confirmed that the major veins were intact despite the failure to inject them. The most massive haemorrhages were seen in the least mature infants, usually those of 24-28 weeks' gestational age, and in 3 there was irregular ex-

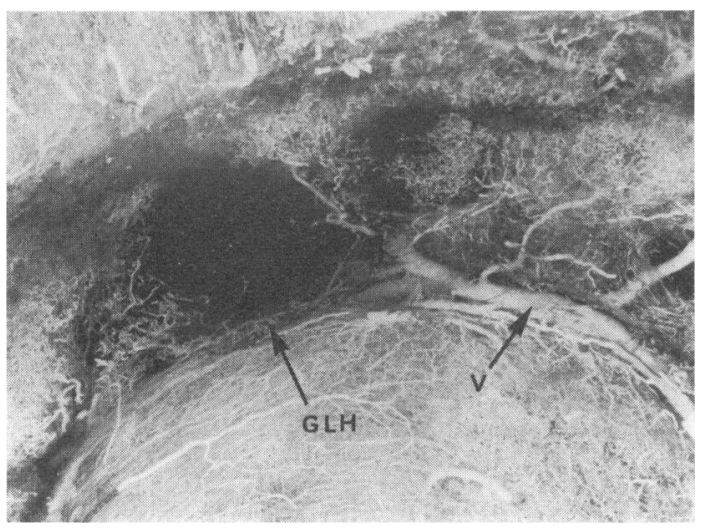

Fig. 8.-Case 4 (cleared and partly dissected). Lateral wall of left lateral ventricle. Intraventricular clot and choroid plexus have been removed to show the GLH and the intact terminal vein, $V . \quad(\times 4$. tension of intracerebral haemorrhage into the white matter lateral to the head and body of the caudate nucleus (Fig. 9). Distended terminal vein branches could be seen in these areas on stereomicroscopic examination, with haemorrhage cuffing some of the vessels.

Artefactual vessel rupture. Small leaks of barium gelatine solution had occurred in 13 of the brains injected through the carotid arteries including 5 injected at measured pressures of $80 \mathrm{mmHg}$ or more. These were most numerous in the germinal layer region though scattered leaks might be seen throughout the cerebral hemispheres. The largest leaks were seen over the head of the caudate nucleus where they mimicked spontaneous GLH (Fig. 10). In 3 instances the injection mass had leaked into the germinal layer at the margin of a spontaneous haemorrhage.

Jugular injection. In the 2 brains injected through the jugular veins the injection mass had distended the venous sinuses, the cortical cerebral veins, the vein of Galen, the internal cerebral vein, and some of the terminal vein branches. The terminal veins were intact in both brains despite extreme congestion of the deep venous system which had ruptured at multiple sites at its junction with the cortical venous system, particularly in the less mature brain (Fig. 11). There was also extensive rupture of small vein branches over the surface 


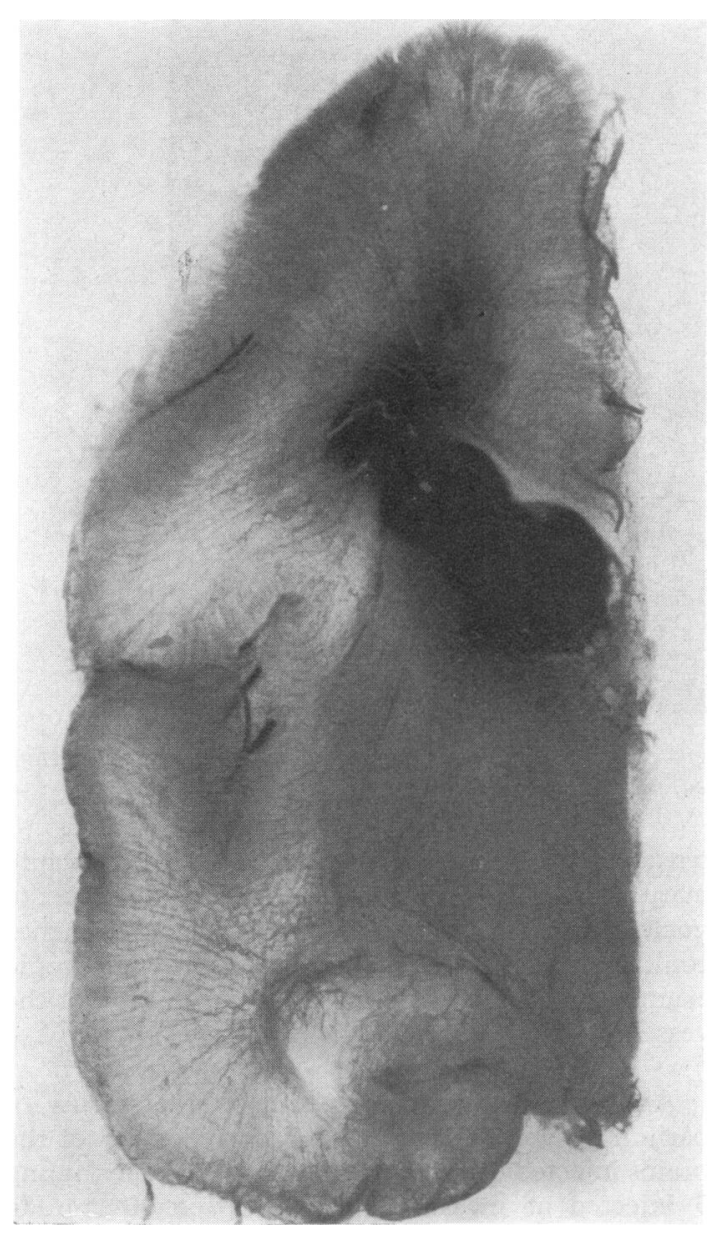

FIG. 9. Case 13 (cleared). Coronal slice of right cerebrum showing GLH with lateral extension into the white matter. $(\times 5$.

of the hemispheres. Two very small GLHs were present in the head of each caudate nucleus in the smaller brain, and an established GLH with intraventricular clot in the left lateral ventricle was present in the larger brain (gestational age 37 weeks).

Origin of GLH. Dissection of haemorrhages under the stereomicroscope and examination of serial and step sections failed to show evidence of rupture of either veins or arteries but showed extensive disruption of the capillary bed. Small GLHs were closely related to veins, sometimes surrounding vein branches, or abutting the ventricular aspect of the vein wall. Sections through one very small haemorrhage showed evidence of

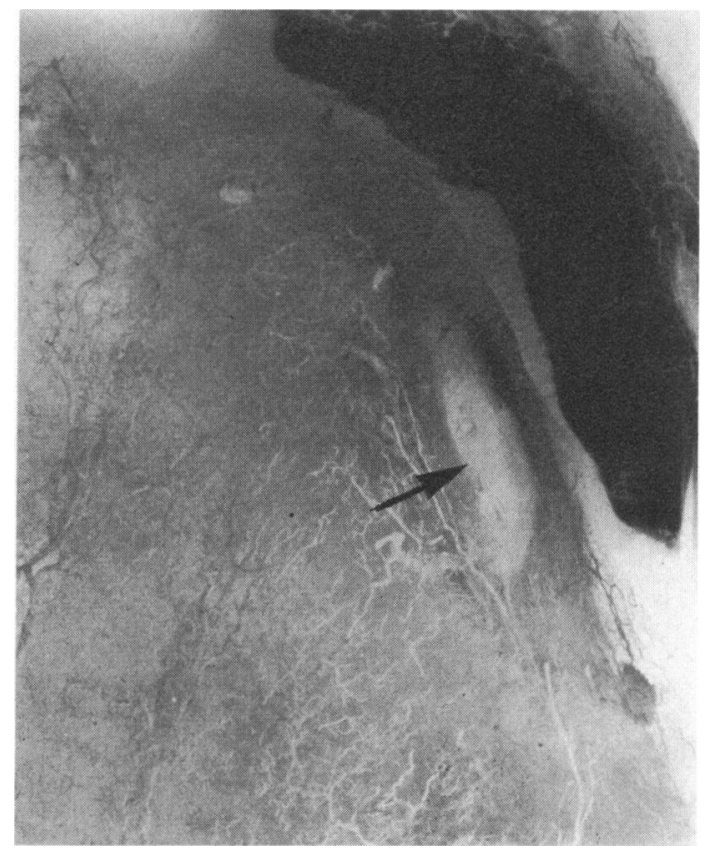

FIG. 10.-Case 1 (cleared). Coronal slice of right cerebrum. Arrow marks a leak of injection mass in the area of distribution of Heubner's artery. The spontaneous GLH at the same site in the opposite hemisphere is shown in Figs. 4 and 5 and is the origin of the IVH seen here at upper right. $(\times 6$.

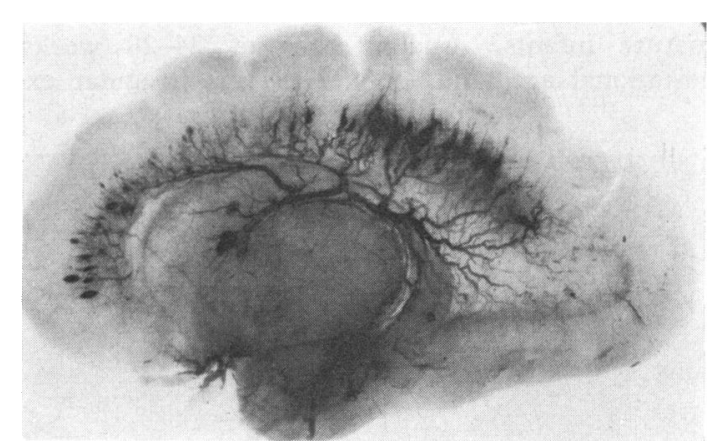

FIG. 11.-Case 8 (cleared). Saggittal section of right cerebrum showing leaks at junction of deep and superficial vein systems caused by jugular injection. Note the 2 small GLHs over the head of the caudate nucleus.

rupture at a capillary-vein junction, with a fibrin plug extending from the lumen of the vein into the haemorrhage (Figs. 12 and 13). Serial sections through other haemorrhages failed to show similar lesions, though small masses of fibrin were seen in 


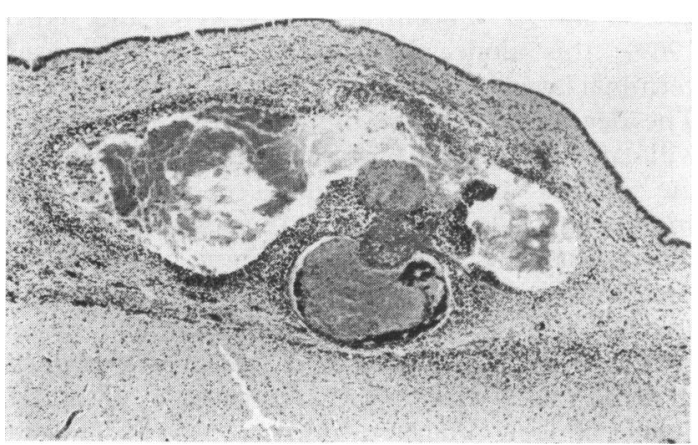

FIG. 12.-Case 6. Section through small GLH. Site of rupture at capillary-vein junction occluded by fibrin thrombus. (H. and E. $\times 20$.)

several of them just outside terminal vein branches. Artefactual leaks of injection mass occurred in the same areas as spontaneous haemorrhages often surrounding, or abutting, vein branches.

The histological appearance of the germinal layer outside the area of haemorrhage was normal, and the vessels could be filled readily by the injection procedure if carried out within 48 hours after death, except in the cases of massive haemorrhage mentioned above.

\section{Discussion}

The technique we have used in this study was designed specifically to show the vascular anatomy of the germinal layer and its relation to GLH. It is perhaps not surprising therefore that the results conflict with those of previous workers who used routine neuropathological methods (Gröntoft, 1953, 1954; Larroche, 1964; Towbin, 1968). Our studies show a rich arterial supply to the germinal layer over the head of the caudate nucleus where most of the haemorrhages occur. Venous drainage is into the terminal vein branches; capillary channels often open at right angles directly into the veins. From the study of serial sections of injected and uninjected specimens it is apparent that the haemorrhages originate from the capillary bed, or occasionally from the capillary vein junctions. We are unable to substantiate the occurrence of terminal vein rupture as claimed by Gröntoft (1953) and Cole et al. (1974).

The theory that GLH is due to rupture of the terminal vein appears to have arisen because the haemorrhages develop close to this vessel. In our material the noninjected veins can seldom be seen on gross examination as they are usually collapsed and empty. Gröntoft (1954) injected a starch and carbon mass at $70 \mathrm{~cm}$ water pressure through the carotid arteries of preterm infants, while applying a pressure of $15-20 \mathrm{~cm}$ water to the veins entering the heart. The leakage of carbon into the germinal layer which occurred in this experiment was attributed to the raised venous pressure. We have produced similar leaks of injection mass by arterial injection without impeding venous drainage. Vein

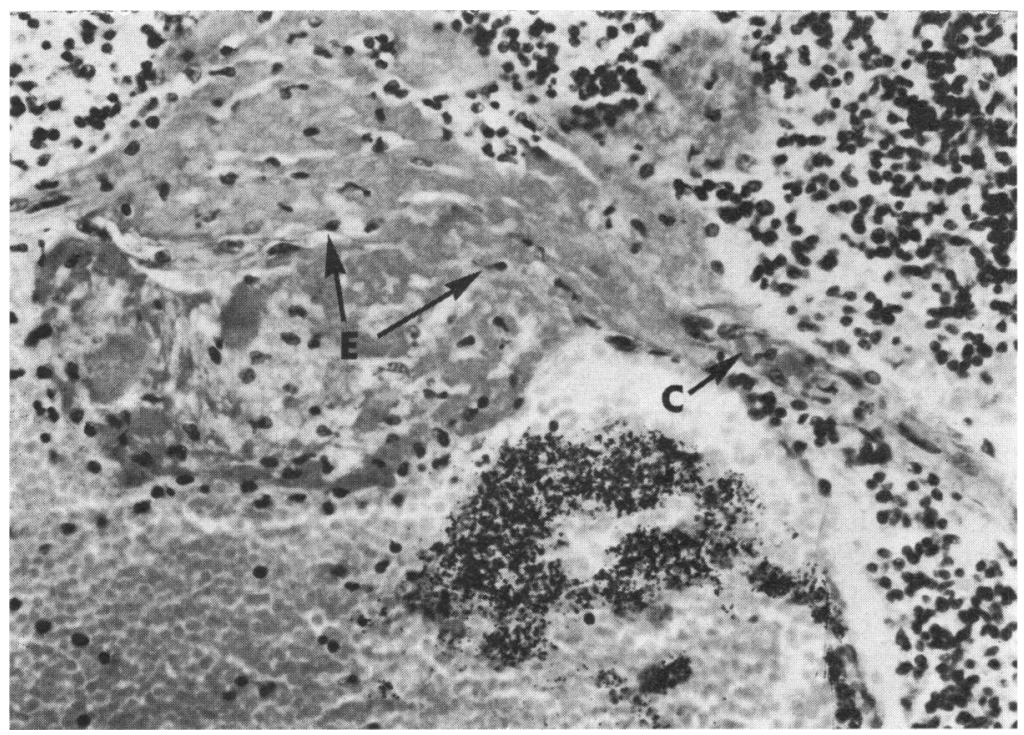

FIG. 13.-Higher magnification of section shown in Fig. 12. ' $E$ ' marks vessel endothelium within thrombus. ' $C$ ' is the capillary which has ruptured. (H. and $E . \times 260$.) 
ruptures caused by jugular injection have been concentrated at the junction of the deep and cortical veins in the white matter, rather than in the germinal layer. When venous congestion and rupture occurs in association with GLH, as in 3 of our cases, this appears to be secondary to obstruction of venous drainage by extensive haemorrhage. Usually the vascular bed of the germinal layer remains intact, except within the localized area of the haemorrhage itself. We are therefore unable to accept the view that germinal layer infarction plays a significant role (Towbin, 1968). Venous thrombosis (Larroche, 1964; Ross and Dimmette, 1965) has not been a feature of our cases though we have seen small fibrin clots, similar to those described by Ross and Dimmette (1965), within and outside terminal vein branches. These are an inconstant finding which we interpret as due to rupture at the capillary-vein junction.

Previous morbid anatomical studies, while focusing attention on the veins, have largely ignored the existence or relevance of an arterial blood supply to the brain. Our injection studies show that the basic pattern of arterial supply to the caudate nucleus in the preterm infant is similar to that described in the adult (Van den Bergh and Vander Eecken, 1968).

However, the arteries concerned are relatively far larger in the preterm infant brain than they are in the adult and must transmit a correspondingly large proportion of the total cerebral blood flow. Much of this flow is directed to the germinal layer capillary bed. In our injected specimens the area where GLH is seen most frequently corresponds precisely to the area of distribution of Heubner's artery.

Although our studies confirm previous work (Hemsath, 1934; Leech and Kohnen, 1974) in showing that most GLHs occur over the head of the caudate nucleus, this does not apply to infants of 28 weeks' gestational age or less in whom the haemorrhages characteristically arise over the body of the caudate nucleus. This variation in site according to gestational age suggests to us that the maturity of the germinal layer capillary bed may be of critical importance in determining where bleeding occurs.

The presence of an immature capillary bed within the germinal layer does not fully explain the occurrence of GLH and IVH since the lesions are rarely seen in stillborn infants, occur a over wide gestational range (see Table), and are particularly associated with the respiratory distress syndrome (Harcke et al., 1972; Leech and Kohnen, 1974). The most likely additional factors are those related to cerebrovascular haemodynamics in the newborn, especially in infants who develop the respiratory distress syndrome. An increase in cerebral blood flow is known to occur at birth (Purves and James, 1969); this alone might be sufficient to rupture germinal layer capillaries in the very immature brain. The development of respiratory distress syndrome will cause a further rise in cerebral blood flow due to the cerebral vasodilatation induced by hypercapnia and hypoxia (Purves, 1972). In such circumstances the mechanisms by which cerebral blood flow is normally maintained independent of changes in arterial pressure may well be abolished (Harper, 1966). Continuous records of blood pressure have shown a rise in arterial pressure of up to $25 \mathrm{mmHg}$ during apnoeic attacks in preterm infants, or when the babies are handled (Chu et al., 1967). The lack of rigidity in the preterm infant skull could in theory allow a rise in blood pressure to cause an increased transmural pressure across cerebral vessels, though it is difficult to estimate how significant this would be at the level of the subependymal capillary bed.

The possibility remains that raised central venous pressure (Cole et al., 1974) could affect circulation through the germinal layer capillary bed and predispose to haemorrhage in this area. It has, however, yet to be established that raised venous pressure commonly occurs in babies who subsequently develop IVH. Indeed, direct measurement in a group of such babies indicated a mean right atrial pressure of $2.9 \mathrm{~cm} \mathrm{H} \mathrm{H}_{2} \mathrm{O}$ despite the use of positive pressure ventilation (Harrison, Heese, and Klein, 1968). The ease with which the capillaries in the germinal layer are ruptured during arterial injection and the paucity of such ruptures during venous injection suggests to us that the arterial pressure is the more important factor.

The large size and catastrophic nature of many cases of GLH and IVH are difficult to reconcile with a capillary bed origin since capillary haemorrhages are usually small and rapidly limited by haemostatic mechanisms. Though there have been a number of claims that haemostatic failure is a feature of babies who develop IVH (e.g. Gray, Ackerman, and Fraser, 1968) it is probable that such haemostatic abnormalities as occur are secondary features of the condition (Chessells and Wigglesworth, 1972). A more plausible explanation for the extensive spread of capillary haemorrhage in the germinal layer is provided by Gilles et al. (1971). These authors noted the conspicuous absence of fibrin in germinal layer haemorrhages and measured the fibrinolytic activity in this area of the brain in preterm infants. High fibrinolytic activity, associated with the presence of plasminogen activator, was shown in the germinal layer tissue, particularly during the period from 22 to 30 weeks' gestation. This could explain the failure of localization of the 
capillary haemorrhage despite normal systemic haemostatic mechanisms.

We suggest as a tentative hypothesis that GLH and subsequent IVH arise if the vessels of the germinal layer capillary bed are subjected to an increase in arterial blood pressure when they are already maximally dilated by hypercapnia and hypoxia. High fibrinolytic activity in the germinal layer may allow propagation of the original haemorrhage. It must be pointed out that some of the assumptions on which this hypothesis is based are speculative since the interaction of different factors involved in control of cerebral blood flow is complex and few studies in this field have been performed on the newborn. If the hypothesis is correct, management of the ill preterm infant needs to be planned to minimize the predisposing factors. This implies meticulous care in monitoring $\mathrm{PaO}_{2}$, acid base status, and blood pressure, preferably using continuous recording methods (Goddard et al., 1974). At the same time it is clearly essential to reduce handling of the infant to a minimum in order to avoid hypertensive episodes.

We thank Professor V. Dubowitz for helpful advice; Dr. Sabina Strich for stimulating discussion on the possible arterial origin of IVH; Mr. D. Wanklyn for skilled technical assistance; and Mr. W. Hinks, Department of Medical Illustration, Royal Postgraduate Medical School, for excellent photography. This work is currently supported by MRC Grant G974/682/N.

\section{REFERENCES}

Chessells, J. M., and Wigglesworth, J. S. (1972). Coagulation studies in preterm infants with repiratory distress and intracranial haemorrhage. Archives of Disease in Childhood, 47, 564.

Chu, J., Clements, J. A., Cotton, E. K., Klaus, M. H., Sweet, A. Y., and Tooley, W. H. (1967). Neonatal pulmonary ischemia. Part 1. Clinical and physiological studies. Pediatrics, 40, 709.

Cole, V. A., Durbin, G. M., Olaffson, A., Reynolds, E. O. R., Rivers, R. P. A., and Smith, J. F. (1974). Pathogenesis of intraventricular haemorrhage in newborn infants. Archives of Disease in Childhood, 49, 722.

Edwards, J. J., and Edwards, M. J. (1959). Medical Museum Technology, p. 137. Oxford University Press, London.
Gilles, F. H., Price, R. A., Kevy, S. V., and Berenberg, W. (1971). Fibrinolytic activity in the ganglionic eminence of the premature human brain. Biology of the Neonate, 18, 426.

Goddard, P., Keith, I., Marcovitch, H., Roberton, N. R. C., Rolfe, P., and Scopes, J. W., (1974). Use of a continuously recording intravascular oxygen electrode in the newborn. Archives of Disease in Childhood, 49, 853.

Gray, O. P., Ackerman, A., and Fraser, A. J. (1968). Intracranial haemorrhage and clotting defects in low-birth-weight infants. Lancet, $1,545$.

Gröntoft, O. (1953). Intracerebral and meningeal haemorrhages in perinatally deceased infants. I. Intracerebral haemorrhages. Acta Obstetricia et Gynecologica Scandinavica, 32, 308.

Gröntoft, O. (1954). Intracranial haemorrhage and blood-brain barrier problems in the newborn. Acta Pathologica et Microbiologica Scandinavica, Suppl. 100.

Gruenwald, P. (1951). Subependymal cerebral haemorrhage in premature infants, and its relation to various injurious influences at birth. American fournal of Obstetrics and Gynecology, 61, 1285.

Harcke, H. T., Naeye, R. L., Storch, A., and Blanc, W. A. (1972). Perinatal cerebral intraventricular hemorrhage. fournal of Pediatrics, 80, 37.

Harper, A. M. (1966) Autoregulation of cerebral blood flow: influence of the arterial blood pressure on the blood flow through the cerebral cortex. Fournal of Neurology, Neurosurgery, and Psychiatry, 29, 398.

Harrison, V. C., Heese, H. de V., and Klein, M. (1968). Intracranial haemorrhage associated with hyaline membrane disease. Archives of Disease in Childhood, 43, 116.

Hemsath, F. A. (1934). Ventricular cerebral haemorrhage in the newborn infant. American fournal of Obstetrics and Gynecology, 28, 343.

Larroche, J. C. (1964). Hemorrhagies cérébrales intra-ventriculaires chez le prématuré. I. Anatomie et pathophysiologie. Biologia Neonatorum, 7, 26.

Leech, R. W., and Kohnen, P. (1974). Subependymal and intraventricular hemorrhages in the newborn. American fournal of Pathology, 77, 465.

Purves, M. J. (1972). Physiology of the Cerebral Circulation, Chaps. 7 and 9. Cambridge University Press, London.

Purves, M. J., and James, I. M. (1969). Observations on the control of cerebral blood flow in the sheep fetus and newborn lamb. Circulation Research, 25, 651.

Reynolds, E. O. R., and Taghizadeh, A. (1974). Improved prognosis of infants mechanically ventilated for hyaline membrane disease. Archives of Disease in Childhood, 49, 505.

Ross, J. J., and Dimmette, R. M. (1965). Subependymal cerebral hemorrhage in infancy. American fournal of Diseases of Children, 110, 531 .

Towbin, A. (1968). Nervous system damage in the human fetus and newborn infant. American fournal of Diseases of Children, 119, 529.

Van den Bergh, R., and Vander Eecken, H. (1968). Anatomy and embryology of cerebral circulation. Progress in Brain Research, Vol. 30, p. 1. Ed. by W. Luyendijk. Elsevier, Amsterdam.

Correspondence to Dr. J. S. Wigglesworth, Neonatal Research Unit, Institute of Child Health, Hammersmith Hospital, Du Cane Road, London W12. 